\title{
A predictive model and nomogram for predicting return to work at 3 months after cervical spine surgery: an analysis from the Quality Outcomes Database
}

\author{
Clinton J. Devin, MD, ${ }^{1}$ Mohamad Bydon, MD, ${ }^{2}$ Mohammed Ali Alvi, MBBS, ${ }^{2}$ \\ Panagiotis Kerezoudis, MD, MS, ${ }^{2}$ Inamullah Khan, MD, ${ }^{1}$ Ahilan Sivaganesan, MD, ${ }^{1}$ \\ Matthew J. McGirt, MD, ${ }^{3}$ Kristin R. Archer, PhD, DPT, ${ }^{4}$ Kevin T. Foley, MD, ${ }^{5}$ \\ Praveen V. Mummaneni, MD, ${ }^{6}$ Erica F. Bisson, MD, MPH, ${ }^{7}$ John J. Knightly, MD, ${ }^{8}$ \\ Christopher I. Shaffrey, MD, ${ }^{9}$ and Anthony L. Asher, MD ${ }^{3}$
}

\begin{abstract}
${ }^{1}$ Department of Orthopedic Surgery and Neurological Surgery, Vanderbilt Spine Center, Vanderbilt University Medical Center, Nashville, Tennessee; ${ }^{2}$ Department of Neurologic Surgery, Mayo Clinic, Rochester, Minnesota; ${ }^{3}$ Department of Neurological Surgery, Carolina Neurosurgery and Spine Associates and Neurological Institute, Carolinas Healthcare System, Charlotte, North Carolina; ${ }^{4}$ Department of Physical Medicine and Rehabilitation, Vanderbilt University Medical Center, Nashville; ${ }^{5}$ Department of Neurosurgery, University of Tennessee Health Sciences Center, Semmes Murphey Neurologic and Spine Institute, Memphis,

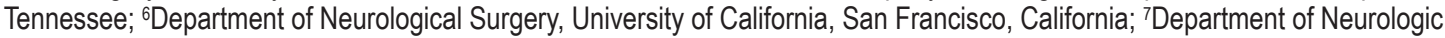
Surgery, University of Utah, Salt Lake City, Utah; ${ }^{8}$ Atlantic Neurosurgical Specialists, Morristown, New Jersey; and ${ }^{9}$ Department of Neurosurgery, University of Virginia Medical Center, Charlottesville, Virginia
\end{abstract}

OBJECTIVE Back pain and neck pain are two of the most common causes of work loss due to disability, which poses an economic burden on society. Due to recent changes in healthcare policies, patient-centered outcomes including return to work have been increasingly prioritized by physicians and hospitals to optimize healthcare delivery. In this study, the authors used a national spine registry to identify clinical factors associated with return to work at 3 months among patients undergoing a cervical spine surgery.

METHODS The authors queried the Quality Outcomes Database registry for information collected from April 2013 through March 2017 for preoperatively employed patients undergoing cervical spine surgery for degenerative spine disease. Covariates included demographic, clinical, and operative variables, and baseline patient-reported outcomes. Multiple imputations were used for missing values and multivariable logistic regression analysis was used to identify factors associated with higher odds of returning to work. Bootstrap resampling (200 iterations) was used to assess the validity of the model. A nomogram was constructed using the results of the multivariable model.

RESULTS A total of 4689 patients were analyzed, of whom $82.2 \%(n=3854)$ returned to work at 3 months postoperatively. Among previously employed and working patients, $89.3 \%(n=3443)$ returned to work compared to $52.3 \%(n=$ 411) among those who were employed but not working (e.g., were on a leave) at the time of surgery $(p<0.001)$. On multivariable logistic regression the authors found that patients who were less likely to return to work were older (age $>56-65$ years: OR 0.69, 95\% Cl 0.57-0.85, $p<0.001$; age > 65 years: OR 0.65, 95\% Cl 0.43-0.97, $p=0.02$ ); were employed but not working (OR 0.24, 95\% Cl 0.20-0.29, p < 0.001); were employed part time (OR 0.56, 95\% Cl 0.42-0.76, p < 0.001); had a heavy-intensity (OR $0.42,95 \% \mathrm{Cl} 0.32-0.54, \mathrm{p}<0.001)$ or medium-intensity $(\mathrm{OR} 0.59,95 \% \mathrm{Cl} 0.46-0.76, \mathrm{p}<$ 0.001 ) occupation compared to a sedentary occupation type; had workers' compensation (OR $0.38,95 \% \mathrm{Cl} 0.28-0.53$, $p<0.001$ ); had a higher Neck Disability Index score at baseline (OR 0.60, 95\% Cl 0.51-0.70, $p=0.017$ ); were more likely to present with myelopathy (OR $0.52,95 \% \mathrm{Cl} 0.42-0.63, \mathrm{p}<0.001)$; and had more levels fused ( $3-5$ levels: OR 0.46 , $95 \% \mathrm{Cl} 0.35-0.61, \mathrm{p}<0.001)$. Using the multivariable analysis, the authors then constructed a nomogram to predict return to work, which was found to have an area under the curve of 0.812 and good validity.

CONCLUSIONS Return to work is a crucial outcome that is being increasingly prioritized for employed patients under-

ABBREVIATIONS ACDF = anterior cervical discectomy and fusion; IQR = interquartile range; NASS = North American Spine Society; NDI = Neck Disability Index; PRO = patient-reported outcome; $\mathrm{QOD}=$ Quality Outcomes Database. SUBMITTED June 25, 2018. ACCEPTED August 20, 2018. INCLUDE WHEN CITING DOI: 10.3171/2018.8.FOCUS18326. 
going spine surgery. The results from this study could help surgeons identify at-risk patients so that preoperative expectations could be discussed more comprehensively.

https://thejns.org/doi/abs/10.3171/2018.8.FOCUS18326

KEYWORDS cervical surgery; return to work; spine surgery; QOD; Quality Outcomes Database

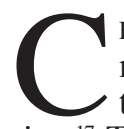

ERVICAL myelopathy and radiculopathy leading to neck pain and arm weakness represent an important cause of disability among the elderly population. ${ }^{17}$ The rate of surgical intervention for cervical spine disease has seen an exponential rise in the last few decades, with an accumulated cost burden of more than $\$ 2$ billion per year according to some estimates. ${ }^{11,19,28}$ In the recent era of rising healthcare scrutiny for providers and institutions and with the added focus on patient-centered outcomes, it has become critical for surgeons to optimize their patient outcomes.

Return to work after surgery represents one such outcome that has been increasingly prioritized in recent years. Loss of work hours due to back- or neck-related pathology is considered a significant economic burden warranting further research and optimization. Previous studies have used single-institution data with limited sample size to evaluate the role of certain clinical and operative factors that can predict return to work, and have shown variable results. ${ }^{13,19}$ There remains a paucity of literature on assessing the role and interplay of various demographic, occupation-related, and clinical variables in determining the probability of return to work after cervical spine surgery.

To address this knowledge gap, this study used data from a national spine registry to construct a predictive model as well as a nomogram to predict return to work after cervical spine surgery among patients who were employed preoperatively.

\section{Methods \\ Data Source}

For this project, we queried the cervical spine module of the Quality Outcomes Database (QOD) registry. The QOD is a prospective registry that was designed to evaluate risk-adjusted expected morbidity and 12-month clinical outcomes, with the objective of improving efficiency and quality of care for the most commonly performed surgical spine procedures. ${ }^{3,22}$ The registry has been enrolling patients since 2012. The cervical spine module of the QOD registry was built in collaboration with the Cervical Spine Research Society and the Joint Section on Disorders of the Spine and Peripheral Nerve in 2013. The cervical module enrolls patients who are undergoing surgery for degenerative cervical spine disease. Details regarding the cervical module can be obtained from the NeuroPoint Alliance website (http://www.neuropoint.org/registries/ qod-spine/\#1519913148052-7431e7be-7f5f). Institutional review board approval and a waiver of consent form from the patients were obtained.

\section{Patient Cohort and Outcome of Interest}

The general inclusion and exclusion criteria for the QOD registry spine modules have previously been listed in detail. ${ }^{3,21,22}$ In addition, for the purposes of the present analysis, patients were included if they met the following criteria: 1) patients undergoing any cervical spine surgery for degenerative cervical spine disease; 2) patients who had complete 3-month information for return to work, which was the primary outcome of interest; and 3) patients who had complete baseline information regarding employment status, type, and intensity. We focused only on patients who were either "employed and working" or "employed but not working" at the time of surgery. We excluded patients who were either unemployed or students at the time of surgery. The exclusion criteria have been summarized in the Supplemental File.

\section{Covariates}

A summary of all the covariates can be found in the Supplemental File and in Tables 1-3.

\section{Statistical Analysis}

Means with standard deviations or medians with interquartile ranges (IQRs) were used to summarize continuous variables, whereas frequencies with proportions were used to summarize categorical variables. Continuous and categorical variables were compared between patients who returned to work at 3 months and those who did not by using a 2 -sided t-test and the chi-square test, respectively. A multivariable logistic regression model was fitted for return-to-work status after adjusting for an array of patient-specific baseline clinical and work-related variables. The Akaike Information Criterion and c-statistic demonstrated the usefulness of the model to discriminate between patients who did not return versus those who did return to work at 3 months. For internal validation of the discrimination and calibration of the model, we used bootstrap resampling (200 iterations) provided by the $\mathrm{rms}$ package to estimate the likely performance of the model on a new sample. This method has been described and previously used in other analyses from the QOD and allows the validation of the model without having to use an external data set. ${ }^{2,15}$ We also tested the absolute importance of each variable that was included in the model on predicting 3-month return to work by using an importance metric defined as Wald chi-square penalized by the predictor degrees of freedom (i.e., Wald chi-square - df). ${ }^{16}$ We used multiple imputations from the rms package to impute missing values; this method used a combination of bootstrapping, additive regression, and predictive mean matching.

Using the results from the multivariable logistic regression model, we created a nomogram with 10 clinically relevant variables, which were found to have a high relative importance in the predictor importance analysis. To create a calibration diagram, we plotted the marginal estimates 
TABLE 1. Univariate analysis of demographic characteristics by return-to-work status

\begin{tabular}{|c|c|c|c|}
\hline \multirow[b]{2}{*}{ Variable } & \multicolumn{2}{|c|}{ Return-to-Work Status } & \multirow{2}{*}{$\begin{array}{c}\mathrm{p} \\
\text { Value }\end{array}$} \\
\hline & No, $n=835$ & Yes, $n=3854$ & \\
\hline Median age at op (IQR) & $52(46-59)$ & $51(45-58)$ & $<0.001$ \\
\hline \multicolumn{4}{|l|}{ Age at op categories, yrs } \\
\hline$<40$ & $83(10.6 \%)$ & $449(12.1 \%)$ & \multirow[t]{4}{*}{0.027} \\
\hline $40-55$ & $389(49.6 \%)$ & $1990(53.7 \%)$ & \\
\hline $56-65$ & $263(33.5 \%)$ & $1061(28.6 \%)$ & \\
\hline$>65$ & $49(6.25 \%)$ & $205(5.53 \%)$ & \\
\hline Female & $387(46.3 \%)$ & $1781(46.2 \%)$ & 0.979 \\
\hline Hispanic or Latino & $25(2.99 \%)$ & $74(1.92 \%)$ & 0.147 \\
\hline \multicolumn{3}{|l|}{ Insurance } & \multirow[t]{6}{*}{$<0.001$} \\
\hline Uninsured & $18(2.18 \%)$ & $20(0.52 \%)$ & \\
\hline Medicare & $48(5.82 \%)$ & $183(4.75 \%)$ & \\
\hline Medicaid & $45(5.45 \%)$ & $74(1.92 \%)$ & \\
\hline Veterans Affairs/government & $20(2.42 \%)$ & $149(3.87 \%)$ & \\
\hline Private & $694(84.1 \%)$ & $3423(88.9 \%)$ & \\
\hline \multicolumn{3}{|l|}{ Education } & \multirow[t]{7}{*}{$<0.001$} \\
\hline$<$ High school & $49(5.88 \%)$ & $81(2.1 \%)$ & \\
\hline $\begin{array}{l}\text { High school diploma or GED } \\
\text { certificate }\end{array}$ & $431(51.7 \%)$ & $1385(36 \%)$ & \\
\hline 2-yr college degree & $154(18.5 \%)$ & $783(20.3 \%)$ & \\
\hline 4-yr college degree & $126(15.1 \%)$ & $928(24.1 \%)$ & \\
\hline Postgraduate & $48(5.76 \%)$ & $620(16.1 \%)$ & \\
\hline Prefer not to answer & $25(3 \%)$ & $51(1.33 \%)$ & \\
\hline \multicolumn{3}{|l|}{ Employment status } & \multirow[t]{3}{*}{$<0.001$} \\
\hline $\begin{array}{l}\text { Employed \& currently } \\
\text { working }\end{array}$ & $460(55.1 \%)$ & $3443(89.3 \%)$ & \\
\hline Employed but not working & $375(44.9 \%)$ & $411(10.7 \%)$ & \\
\hline \multicolumn{3}{|l|}{ Employment type } & \multirow[t]{3}{*}{$<0.001$} \\
\hline Full time & $381(83.2 \%)$ & $3144(91.5 \%)$ & \\
\hline Part time & $77(16.8 \%)$ & $293(8.52 \%)$ & \\
\hline \multicolumn{3}{|l|}{ Occupation type } & \multirow[t]{5}{*}{$<0.001$} \\
\hline Sedentary & $152(18.4 \%)$ & $1380(35.9 \%)$ & \\
\hline Light & $141(17.1 \%)$ & $909(23.6 \%)$ & \\
\hline Medium & $234(28.3 \%)$ & $912(23.7 \%)$ & \\
\hline Heavy & $299(36.2 \%)$ & $644(16.7 \%)$ & \\
\hline Workers' compensation & $123(14.7 \%)$ & $110(2.85 \%)$ & $<0.001$ \\
\hline
\end{tabular}

GED = general equivalency development.

Values were missing for some variables, so denominators and percentages vary among categories. Boldface type indicates statistical significance.

versus the model average predictive probability. Ideally the predictions should consolidate on a $45^{\circ}$ diagonal line in a perfectly calibrated model. Analysis was performed using R version 3.1.2 (https://www.r-project.org) and the rms package. ${ }^{16}$

\section{Results}

Of the 25,178 patients enrolled in the cervical module, 6570 patients (26.1\%) were employed preoperatively.
TABLE 2. Univariate analysis of clinical and operative characteristics by return-to-work status

\begin{tabular}{|c|c|c|c|}
\hline \multirow[b]{2}{*}{ Variable } & \multicolumn{2}{|c|}{ Return-to-Work Status } & \multirow{2}{*}{$\begin{array}{c}\mathrm{p} \\
\text { Value }\end{array}$} \\
\hline & No, $n=835$ & Yes, $n=3854$ & \\
\hline Smoker & $229(27.48 \%)$ & $710(18.68 \%)$ & $<0.001$ \\
\hline Diabetes & $125(15 \%)$ & $455(11.8 \%)$ & 0.036 \\
\hline Coronary artery disease & $65(7.81 \%)$ & $182(4.73 \%)$ & 0.001 \\
\hline $\begin{array}{l}\text { Peripheral vascular } \\
\text { disease }\end{array}$ & $11(1.97 \%)$ & $27(1.09 \%)$ & 0.225 \\
\hline Anxiety & $170(20.4 \%)$ & $651(16.9 \%)$ & 0.054 \\
\hline Depression & $194(23.3 \%)$ & $667(17.3 \%)$ & $<0.001$ \\
\hline Osteoarthritis & $130(23.3 \%)$ & $428(17.3 \%)$ & $<0.001$ \\
\hline Osteoporosis & $16(1.9 \%)$ & $67(1.7 \%)$ & 0.127 \\
\hline Median BMI (IQR) & $30.3(25.8-33.6)$ & $30.2(25.6-34)$ & 0.881 \\
\hline \multicolumn{3}{|l|}{ ASA grade } & \multirow[t]{6}{*}{$<0.001$} \\
\hline 1 & $33(4.04 \%)$ & $360(9.5 \%)$ & \\
\hline 2 & $510(62.4 \%)$ & $2521(66.5 \%)$ & \\
\hline 3 & $267(32.7 \%)$ & $891(23.5 \%)$ & \\
\hline 4 & $7(0.857 \%)$ & $18(0.475 \%)$ & \\
\hline 5 & $0(0 \%)$ & $0(0 \%)$ & \\
\hline \multicolumn{3}{|l|}{ Symptom duration, mos } & \multirow[t]{4}{*}{0.003} \\
\hline$<3$ & $96(11.5 \%)$ & $641(16.7 \%)$ & \\
\hline $3-12$ & $352(42.3 \%)$ & $1506(39.2 \%)$ & \\
\hline$>12$ & $346(41.6 \%)$ & $1540(40.1 \%)$ & \\
\hline \multicolumn{3}{|l|}{ Predominant symptom } & \multirow[t]{4}{*}{$<0.001$} \\
\hline $\begin{array}{l}\text { Radiculopathy w/ or } \\
\text { w/o neck pain }\end{array}$ & $524(63 \%)$ & $2931(76.2 \%)$ & \\
\hline $\begin{array}{l}\text { Myelopathy w/ or w/o } \\
\text { neck or arm pain }\end{array}$ & $286(34.4 \%)$ & $855(22.2 \%)$ & \\
\hline $\begin{array}{l}\text { Mechanical neck pain } \\
\text { from documented } \\
\text { cervical instability }\end{array}$ & $14(1.68 \%)$ & $54(1.4 \%)$ & \\
\hline \multicolumn{3}{|l|}{ Ambulation } & \multirow[t]{3}{*}{$<0.001$} \\
\hline Independent & $782(94 \%)$ & $3794(98.6 \%)$ & \\
\hline Not independent & $50(6.2 \%)$ & $52(1.35 \%)$ & \\
\hline Motor deficit & $342(41.2 \%)$ & $1436(37.3 \%)$ & 0.044 \\
\hline Central stenosis & $360(43.1 \%)$ & 1937 (50.3\%) & $<0.001$ \\
\hline Disc herniation & $307(36.8 \%)$ & $1322(34.3 \%)$ & 0.188 \\
\hline Foraminal stenosis & $290(34.2 \%)$ & $1061(27.2 \%)$ & $<0.001$ \\
\hline Cervical instability & $19(2.28 \%)$ & $86(2.23 \%)$ & 0.99 \\
\hline Pseudarthrosis & $6(0.719 \%)$ & $17(0.441 \%)$ & 0.443 \\
\hline $\begin{array}{l}\text { Adjacent-segment } \\
\text { disease }\end{array}$ & $29(3.47 \%)$ & $63(1.63 \%)$ & $<0.001$ \\
\hline ACDF & $683(98.3 \%)$ & $3123(95.9 \%)$ & 0.004 \\
\hline Minimally invasive & $68(12.2 \%)$ & $348(14.4 \%)$ & 0.214 \\
\hline \multicolumn{3}{|l|}{ No. of levels fused } & \multirow[t]{4}{*}{$<0.001$} \\
\hline 1 & $260(31.1 \%)$ & $1501(38.9 \%)$ & \\
\hline 2 & $271(32.4 \%)$ & $1258(32.6 \%)$ & \\
\hline $3-5$ & $152(18.2 \%)$ & $363(9.4 \%)$ & \\
\hline
\end{tabular}

ASA $=$ American Society of Anesthesiologists.

Values were missing for some variables, so denominators and percentages vary among categories. Boldface type indicates statistical significance. 
TABLE 3. Univariate analysis of baseline and 3-month PROs by return-to-work status

\begin{tabular}{|c|c|c|c|}
\hline \multirow[b]{2}{*}{ Variable } & \multicolumn{2}{|c|}{ Return-to-Work Status } & \multirow[b]{2}{*}{$\begin{array}{c}\mathrm{p} \\
\text { Value }\end{array}$} \\
\hline & $\begin{array}{c}\text { No, } \\
n=835\end{array}$ & $\begin{array}{c}\text { Yes, } \\
n=3854\end{array}$ & \\
\hline \multicolumn{4}{|l|}{ Baseline PROs } \\
\hline NDI score (mean \pm SD) & $23.2 \pm 8.7$ & $18.5 \pm 8.2$ & $<0.001$ \\
\hline VAS score arm (mean \pm SD) & $7 \pm 3$ & $6.4 \pm 3$ & $<0.001$ \\
\hline VAS score neck (mean \pm SD) & $7.5 \pm 2.8$ & $6.7 \pm 2.82$ & $<0.001$ \\
\hline \multicolumn{4}{|l|}{ 3-mo PROs } \\
\hline NDI score (mean \pm SD) & $16.6 \pm 9.4$ & $7.37 \pm 6.79$ & $<0.001$ \\
\hline VAS score arm (mean \pm SD) & $4.1 \pm 3.1$ & $2.37 \pm 2.1$ & $<0.001$ \\
\hline VAS score neck (mean \pm SD) & $4.8 \pm 2.7$ & $3 \pm 2.2$ & $<0.001$ \\
\hline Change in NDI (mean \pm SD) & $6.7 \pm 9.2$ & $11.1 \pm 8.7$ & $<0.001$ \\
\hline $\begin{array}{l}\text { Change in neck pain (mean } \pm \\
\text { SD) }\end{array}$ & $2.7 \pm 3$ & $3.6 \pm 3.1$ & $<0.001$ \\
\hline Change in arm pain (mean \pm SD) & $2.4 \pm 3$ & $3.2 \pm 3$ & $<0.001$ \\
\hline $\begin{array}{l}\text { NASS patient satisfaction at } 3 \\
\text { mos }\end{array}$ & & & $<0.001$ \\
\hline $\begin{array}{l}\text { Surgery met my expecta- } \\
\text { tions. }\end{array}$ & $430(51.7 \%)$ & $2919(76 \%)$ & \\
\hline $\begin{array}{l}\text { I did not improve as much } \\
\text { as I had hoped but I } \\
\text { would undergo the same } \\
\text { operation for the same } \\
\text { results. }\end{array}$ & $249(30 \%)$ & $690(18 \%)$ & \\
\hline $\begin{array}{l}\text { Surgery helped but I would } \\
\text { not undergo the same } \\
\text { operation for the same } \\
\text { results. }\end{array}$ & $58(6.98 \%)$ & $95(2.47 \%)$ & \\
\hline $\begin{array}{l}\text { I am the same or worse } \\
\text { as compared to before } \\
\text { surgery. }\end{array}$ & $94(11.3 \%)$ & $137(3.57 \%)$ & \\
\hline
\end{tabular}

VAS = visual analog scale.

Some patients did not complete the questionnaire at 3 months, so numbers for the return-to-work categories do not match the totals in headings. Boldface type indicates statistical significance.

Among those, 4689 (71.4\%) had completed a 3-month interview and provided information regarding 3-month return-to-work status. Of the 4689 patients included in the analysis, 3903 (83.2\%) were employed and working preoperatively, whereas the remaining patients were employed but not working (e.g., were on a leave). Overall, a total of $3854(82.2 \%)$ patients returned to work within 3 months of surgery. Among previously employed and working patients, $89.3 \%(\mathrm{n}=3443 / 3903)$ returned to work compared to $52.3 \%(\mathrm{n}=411 / 786)$ among those who were employed but not working $(\mathrm{p}<0.001)$.

\section{Demographic Characteristics}

The demographic characteristics of the cohort stratified by return-to-work status are summarized in Table 1 . Patients who returned to work were slightly younger compared to those who did not (51 years [IQR 45-58] vs 52 years [IQR 46-59], $\mathrm{p}<0.001)$. Female sex $(46.3 \%$ [ $=$
387] for no return to work vs $46.2 \%$ [ $\mathrm{n}=1781]$ for return to work, $\mathrm{p}=0.97$ ) and ethnicity (Hispanic or Latino $=3 \%$ $[n=25]$ for no return to work vs $1.92 \%[n=74]$ for return to work, $\mathrm{p}=0.14$ ) had similar distribution between the 2 groups. Patients who returned to work were more likely to have a higher education status (postgraduate: $16.1 \%$ [n = 620 ] vs $5.7 \%$ [n $=48]$; 4-year college: $24.1 \%[n=928]$ vs $15.1 \%$ [ $=126]$; 2 -year college: $20.3 \%$ [ $=783$ ] vs $18.5 \%$ $[\mathrm{n}=154] ; \mathrm{p}<0.001)$. Furthermore, patients who returned to work were more likely to be employed full time $(91.5 \%$ [ $\mathrm{n}=3144]$ vs $83.2 \%$ [ $=381], \mathrm{p}<0.001)$; were more likely to have a sedentary or light-intensity occupation (35.9\% [n $=1380]$ and $23.6 \%[\mathrm{n}=909]$ for sedentary vs $18.4 \%[\mathrm{n}=$ $152]$ and $17.1 \%$ [ $=141]$ for light intensity, $\mathrm{p}<0.001)$; and were less likely to have workers' compensation $(2.85 \%$ [n $=110]$ vs $14.7 \%[\mathrm{n}=123], \mathrm{p}<0.001)$.

\section{Clinical and Operative Characteristics}

Clinical and operative characteristics of the cohort are summarized in Table 2. Patients who returned to work were less likely to be smokers $(18.68 \%$ [ $n=710]$ vs $27.48 \%$ $[\mathrm{n}=229], \mathrm{p}<0.001)$ or to have a history of diabetes $(11.8 \%$ $[\mathrm{n}=455]$ vs $15 \%[\mathrm{n}=125], \mathrm{p}=0.036)$; coronary artery disease $(4.73 \%[\mathrm{n}=182]$ vs $7.81 \%[\mathrm{n}=65], \mathrm{p}=0.001)$; depression $(17.3 \%$ [ $=667]$ vs $23.3 \%[n=194], p<0.001)$; or osteoarthritis $(17.3 \%$ [ $\mathrm{n}=428]$ vs $23.3 \%$ [n=130], $\mathrm{p}<$ $0.001)$. Patients who returned to work were also less likely to present with myelopathy $(22.2 \%[\mathrm{n}=855]$ vs $34.4 \%$ [n $=286], \mathrm{p}<0.001)$; less likely to present with a motor deficit $(37.3 \%$ [ $=1436]$ vs $41.2 \%$ [ $=342], \mathrm{p}<0.044)$; and more likely to be ambulating well at presentation $(98.6 \%$ $[\mathrm{n}=3794]$ vs $94 \%$ [ $=782], \mathrm{p}<0.001)$. Finally, patients who returned to work had a lower number of levels fused compared to those who did not return to work (3-5 levels: $9.4 \%[\mathrm{n}=363]$ vs $18.2 \%[\mathrm{n}=152], \mathrm{p}<0.001)$.

\section{Baseline and 3-Month Patient-Reported Outcomes}

At baseline visit, patients who returned to work were found to have a lower Neck Disability Index (NDI) score $(18.5 \pm 8.2$ vs $23.2 \pm 8.7, \mathrm{p}<0.001)$; less arm pain $(6.4 \pm$ 3 vs $7 \pm 3, \mathrm{p}<0.001)$; and less neck pain $(6.7 \pm 2.82$ vs $7.5 \pm 2.8, \mathrm{p}<0.001)$. Similarly, at 3 months, patients who returned to work were found to have a lower NDI (7.37 \pm 6.79 vs $16.6 \pm 9.4, \mathrm{p}<0.001)$; less arm pain $(2.37 \pm 2.1$ vs $4.1 \pm 3.1, \mathrm{p}<0.001)$; and less neck pain $(3 \pm 2.2$ vs 4.8 $\pm 2.7, \mathrm{p}<0.001)$. Patients who returned to work achieved a higher change in their NDI $(11.1 \pm 8.7$ vs $6.7 \pm 9.2$, p $<0.001)$; neck pain $(3.6 \pm 3.1$ vs $2.7 \pm 3$, p < 0.001); and arm pain $(3.2 \pm 3$ vs $2.4 \pm 3$, p $<0.001)$. Moreover, patients who returned to work were more likely to be satisfied at 3 months, as per the North American Spine Society (NASS) satisfaction score (NASS satisfaction 1 [Surgery met my expectations]: $76 \%$ [ $n=2919]$ vs $51.7 \%[\mathrm{n}=430]$, $\mathrm{p}<0.001$ ) (Table 3).

\section{Predictive Model for Return to Work}

The results from the multivariable logistic regression analysis are summarized in Table 4 and graphically presented in Fig. 1. After adjusting for an array of patient characteristics, the analysis revealed that older patients (age > 
55-65 years: OR $0.69,95 \%$ CI $0.57-0.85, \mathrm{p}<0.001 ;>65$ years: OR $0.65,95 \%$ CI $0.43-0.97, \mathrm{p}=0.02$; reference: age 40-55 years) and patients who had a history of depression (OR 0.75, 95\% CI $0.61-0.93, \mathrm{p}=0.009$ ) were less likely to return to work. We also found that patients with higher education status were more likely to return to work (postgraduate: OR 2.57, 95\% CI 1.81-3.64, $\mathrm{p}<0.001$; 4-year college: OR 1.42, 95\% CI 1.11-1.81, p < 0.001; 2-year college: OR 1.38, 95\% CI 1.09-1.74, $\mathrm{p}=0.02$; reference $=$ high school). Furthermore, patients who were employed but not working compared to those who were working preoperatively were found to be 4 times less likely to return to work at 3 months (OR 0.24, 95\% CI 0.20-0.29, p < 0.001). We also found that patients who were employed part time (OR $0.56,95 \%$ CI $0.42-0.76, \mathrm{p}<0.001)$ and those with workers' compensation (OR $0.38,95 \%$ CI $0.28-0.53$, p < 0.001 ) were less likely to return to work at 3 months. Finally, we found that patients who had trouble ambulating at presentation (OR 0.45, 95\% CI 0.27-0.74, $\mathrm{p}=0.001)$; those who had myelopathy as the predominant symptom (OR 0.52 , 95\% CI $0.42-0.63, \mathrm{p}<0.001)$; those who had more levels fused (3-5 levels: OR 0.46, 95\% CI 0.35-0.61, p < 0.001; reference: 1 level); and those who had a higher baseline NDI score (OR 0.60, 95\% CI 0.51-0.70, $\mathrm{p}=0.017$ ) were less likely to return to work, whereas patients with shorter symptom duration were more likely to return to work $(<3$ months: OR 1.99, 95\% CI 1.49-2.65, p < 0.001).

The adjusted relative importance of each predictor variable has been summarized in Fig. 2. The most important variables -in descending order-were found to be employment status, occupation intensity, predominant symptom, baseline NDI, patient education level, number of levels fused, workers' compensation, symptom duration, age at surgery, and employment type.

\section{Nomogram Development and Validation}

Variables that were considered clinically significant and that were also found to be important in predictor importance analysis were then proposed to be added in the nomogram. After a consensus among coauthors, 10 variables were added in the final model. These included age at surgery, employment type (full time vs part time), patient education level, employment status, occupation intensity, workers' compensation, baseline NDI score, symptom duration, predominant symptom, and number of levels fused (Fig. 3). As highlighted in Supplemental Table 1, the original and the optimism-corrected c-index of the model were each found to be 0.80 . The calibration plot in Supplemental Fig. 2 demonstrates the good performance of the model over a wide range of predicted probabilities when the model is tested on a new set of data, as demonstrated by the close proximity of the actual and predicted probabilities. The final points scheme for the nomogram has been summarized in Supplemental Table 2.

We demonstrate the utility of the nomogram by using 2 illustrative cases (Table 5). The first patient was a 57-yearold man, a high school graduate who presented with neck pain with occasional numbness and tingling, but no weakness. He had experienced these symptoms for more than a year but they had worsened over the preceding 3 months. He was currently employed but had not been going to
TABLE 4. Multivariable logistic regression for predicting return to work

\begin{tabular}{|c|c|c|c|c|}
\hline Variable & OR & $\begin{array}{l}\text { Lower } \\
95 \% \mathrm{Cl}\end{array}$ & $\begin{array}{l}\text { Upper } \\
95 \% \mathrm{Cl}\end{array}$ & $\begin{array}{c}\mathrm{p} \\
\text { Value }\end{array}$ \\
\hline \multicolumn{5}{|l|}{ Age at op, yrs } \\
\hline$<40$ vs $40-55$ & 1.00 & 0.74 & 1.34 & 0.3 \\
\hline $56-65$ vs $40-55$ & 0.69 & 0.57 & 0.85 & $<0.001$ \\
\hline$>65$ vs $40-55$ & 0.65 & 0.43 & 0.97 & 0.02 \\
\hline Female vs male & 0.95 & 0.79 & 1.15 & 0.48 \\
\hline \multicolumn{5}{|l|}{ Education } \\
\hline$<$ High school vs high school & 0.71 & 0.46 & 1.09 & 0.20 \\
\hline 2 yrs college vs high school & 1.38 & 1.09 & 1.74 & 0.02 \\
\hline 4 yrs college vs high school & 1.42 & 1.11 & 1.81 & $<0.001$ \\
\hline Postgraduate vs high school & 2.57 & 1.81 & 3.64 & $<0.001$ \\
\hline $\begin{array}{l}\text { Hispanic or Latino vs not } \\
\text { Hispanic or Latino }\end{array}$ & 0.65 & 0.38 & 1.10 & 0.2 \\
\hline $\begin{array}{l}\text { Employed but not working vs } \\
\text { currently working }\end{array}$ & 0.24 & 0.20 & 0.29 & $<0.001$ \\
\hline Part time vs full time & 0.56 & 0.42 & 0.76 & $<0.001$ \\
\hline \multicolumn{5}{|l|}{ Occupation intensity } \\
\hline Heavy vs sedentary & 0.42 & 0.32 & 0.54 & $<0.001$ \\
\hline Medium vs sedentary & 0.59 & 0.46 & 0.76 & $<0.001$ \\
\hline Light vs sedentary & 0.86 & 0.66 & 1.13 & 0.33 \\
\hline Workers' compensation & 0.38 & 0.28 & 0.53 & $<0.001$ \\
\hline \multicolumn{5}{|l|}{ Predominant symptom } \\
\hline Myelopathy vs radiculopathy & 0.52 & 0.42 & 0.63 & $<0.001$ \\
\hline Mechanical vs radiculopathy & 0.72 & 0.37 & 1.41 & 0.68 \\
\hline \multicolumn{5}{|l|}{ Symptom duration, mos } \\
\hline $3-12$ vs $>12$ & 1.10 & 0.91 & 1.33 & 0.3751 \\
\hline$<3$ vs $>12$ & 1.99 & 1.49 & 2.65 & $<0.001$ \\
\hline Osteoporosis & 1.14 & 0.61 & 2.11 & 0.69 \\
\hline Depression & 0.75 & 0.61 & 0.93 & 0.009 \\
\hline $\begin{array}{l}\text { Ambulation: not independent vs } \\
\text { independent }\end{array}$ & 0.45 & 0.27 & 0.74 & 0.001 \\
\hline Motor deficit & 0.92 & 0.77 & 1.11 & 0.37 \\
\hline \multicolumn{5}{|l|}{ Baseline } \\
\hline Arm pain VAS score & 1.05 & 0.87 & 1.27 & 0.23 \\
\hline Neck pain VAS score & 0.90 & 0.75 & 1.09 & 0.1 \\
\hline NDI score & 0.60 & 0.51 & 0.70 & 0.017 \\
\hline \multicolumn{5}{|l|}{ No. of fused levels } \\
\hline 2 vs 1 & 0.81 & 0.66 & 1.00 & 0.04 \\
\hline $3-5$ vs 1 & 0.46 & 0.35 & 0.61 & $<0.001$ \\
\hline
\end{tabular}

work for the prior 2 months and had obtained workers' compensation. The patient reported his occupation to be of medium intensity, and he only worked part time. Finally, the NDI of this patient was 25. A 1-level anterior cervical discectomy and fusion (ACDF) was planned to address his symptoms. The total score for this patient, as per the nomogram modeling, sums up to 151 points, giving a very low probability of returning to work (i.e., $<20 \%$ ). 


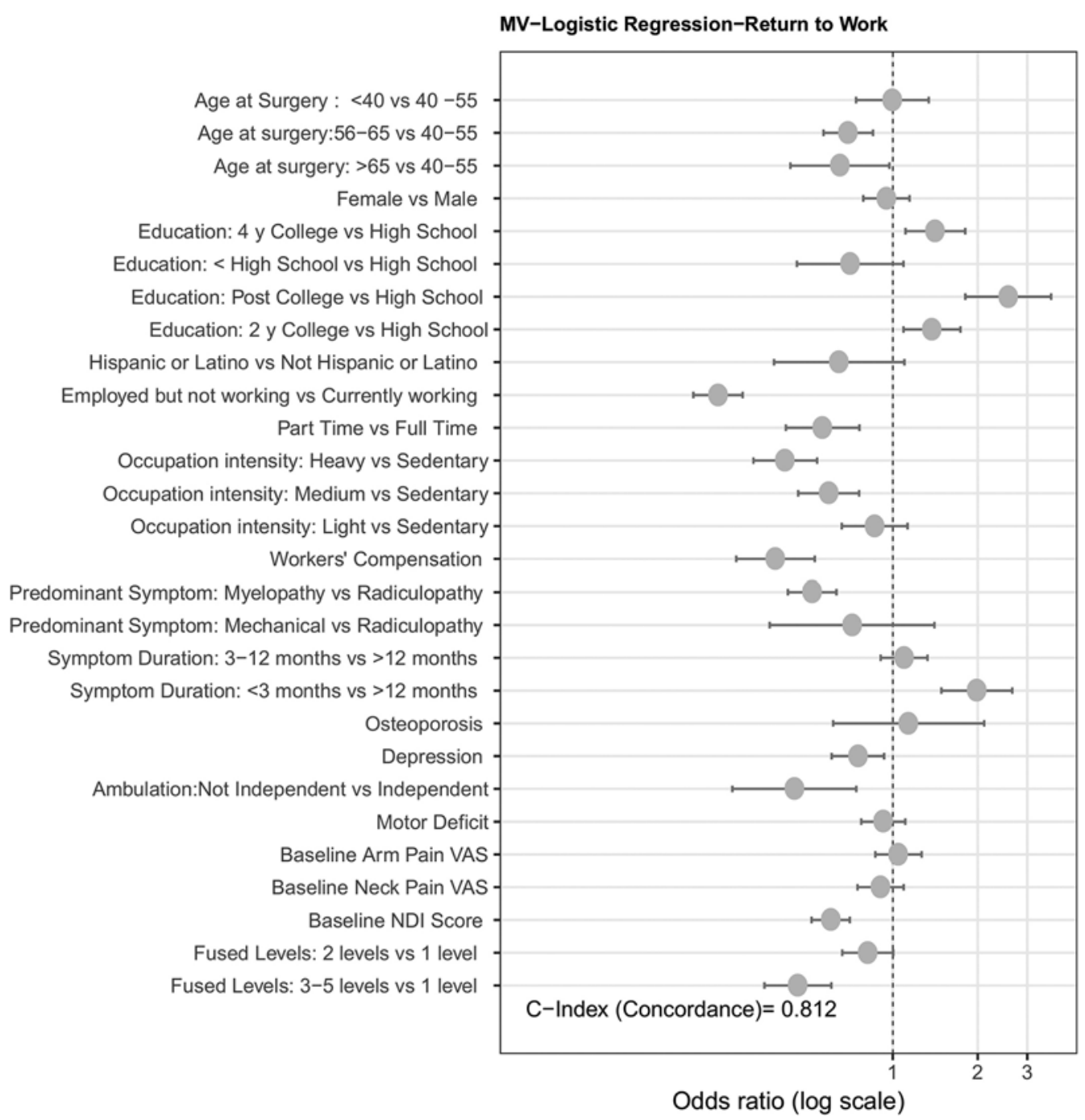

FIG. 1. Multivariable logistic regression model for predicting return to work at 3 months after cervical spine surgery. MV $=$ multivariable; VAS = visual analog scale.

The second patient was a 41-year-old woman, a business school graduate, who presented with predominantly myelopathic signs. The patient was currently employed and working full time at an office where she had a desk job. Her NDI score was high (30). She was found to have cervical spondylotic myelopathy, and a 2-level ACDF was planned to address this surgically. The total score for this patient sums up to 291, giving a probability of $90 \%$ for this patient returning to work.

\section{Discussion}

Return to work is being increasingly used as the benchmark for the standard of operative care for providers and institutions. In this study, we used a national spine registry to construct a predictive model for return to work among patients undergoing cervical spine surgery. We found that younger patients, patients with higher education status, patients employed and working preoperatively, those employed full time, those with a lower-intensity occupation, and those with shorter symptom duration were more likely to return to work after a cervical spine surgery.

Our results suggest that work-related factors might be the most important predictors of return to work after 3 months. Asher et al. analyzed 4695 patients undergoing elective lumbar surgery for degenerative lumbar disease and found that work-related factors accounted for $33.3 \%$ of predictability of a patient returning to work postoperative$\mathrm{ly}^{2}$ In our analysis, the most important predictor of return to work was the employment status preoperatively (i.e., currently working vs not working). A study by Anderson et al. revealed that patients who were working at the time of surgery were 10 times more likely to return to work after a lumbar fusion, ${ }^{1}$ showing that time away from work at the time of presentation is in itself a strong predictor of the patient not returning to work postoperatively. This could be theoretically attributed to the severity of pathology that such patients present with at the time of surgery. For instance, patients employed but not working might have a high-grade spondylolisthesis secondary to a work-related 


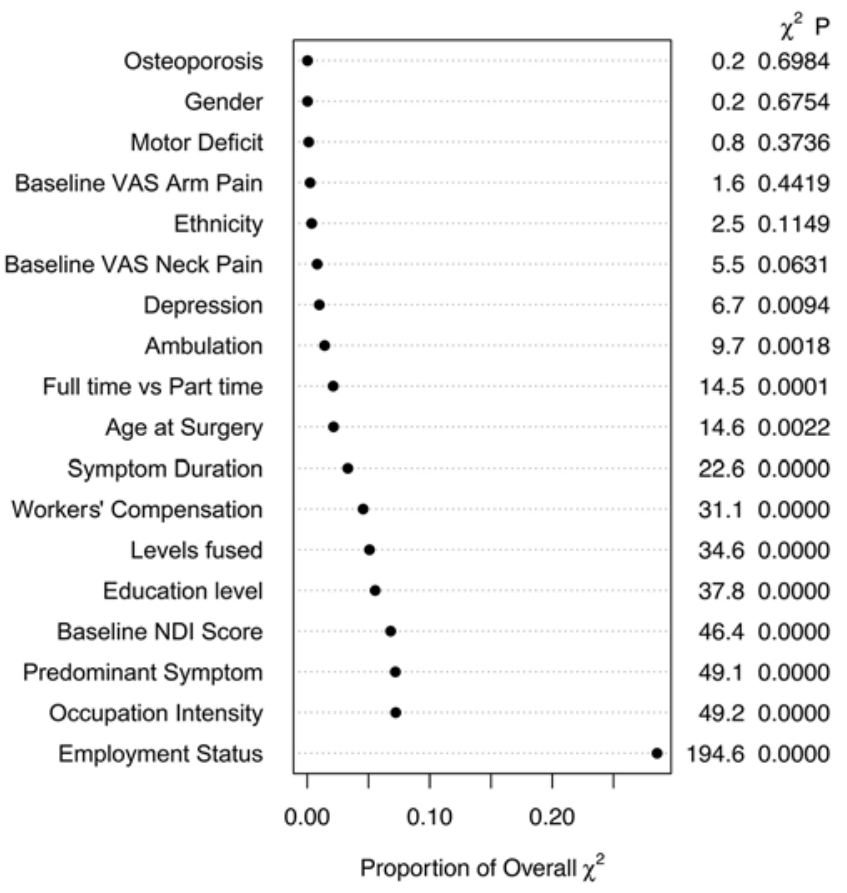

FIG. 2. Predictor importance analysis of variables in the multivariable logistic regression model.

injury, compared to a mild disc herniation or a degenerative disc pathology. We also found that part-time workers were less likely to return to work.

Previous studies have reported a variable effect of employment type on outcomes after spine surgery. ${ }^{7,9,12,26}$ The intensity of occupation, more than the type, was also found to be an important predictor in our cohort, with patients employed in a heavy- or medium-intensity compared to a sedentary job being at risk of failing to return to work. This finding could once again be supported by the assumption that these might represent a cohort of patients employed in a factory or warehouse who present with more severe pathologies such as traumatic fracture or high-grade spondylolisthesis. Additionally, this might be related to more sociological factors such as employeremployee relations, work environment, litigation issues, and social support, all of which have been demonstrated in previous studies to have an adverse impact on outcomes. ${ }^{1,8,13,20,23}$ Finally, we also found that workers' compensation was associated with lower odds of returning to work. Several studies have shown that such financial incentives are greatly associated with lower odds of returning to work..$^{4,5,11,13}$

We also found some demographic factors to have a strong association with return to work. Higher education status was positively associated with return to work; patients with a postgraduate degree, 4-year college degree, and 2-year college degree were more likely to return to work compared to high school graduates or those with even lower education levels. This could possibly be a result of residual confounding, in which a variable that incompletely defines a broader group of variables or is serving as a surrogate turns out to be significantly associated with the outcome. Hence, in this case, these patients with high education levels may also have higher income and a higher socioeconomic status, resulting in having greater access to resources that enable them to return to work successfully. ${ }^{2,18,27}$

Certain clinical factors were also found to be associated with the odds of returning to work. In our cohort, patients presenting with myelopathic symptoms, compared to radiculopathic or mechanical symptoms alone, were less likely to return to work. The presence of myelopathy has been shown to reflect a more severe disease state leading to more adverse patient-reported outcomes (PROs). ${ }^{24}$ Similarly, patients with higher baseline NDI score were also found to be at risk of not returning to work. Peolsson and Peolsson analyzed 95 patients undergoing ACDF and found that a low NDI at baseline was associated with better long-term outcomes. ${ }^{25}$ Furthermore, patients with impaired ambulation at baseline were also at risk of not returning to work. These patients have been shown to require more rehabilitation postoperatively, which in turn may adversely impact their chances of returning to work. ${ }^{2}$ We also found that longer duration of symptoms was associated with lower odds of returning to work. This has been demonstrated in several studies previously. ${ }^{6,10,14}$ Finally, we found that a higher number of levels fused was also associated with lower odds of returning to work. This can be assumed to be secondary to reduced mobility resulting from the higher number of levels fused..$^{29}$

\section{Nomogram Utility}

Nomograms allow for better visual and graphic representation of a predictive model. They can also be used as a bedside tool or a clinic tool for a surgeon to make a quick estimate of an outcome based on readily available information. ${ }^{19}$ The prognostic importance of each variable in the model can be estimated from the number of points along the horizontal axis attributed for that particular variable. Institutions and providers may use return-towork findings to benchmark and leverage their outcomes to negotiate contracts with big companies. Acknowledging this importance, we constructed a nomogram for predicting return to work in which only 10 of the most important predictors of that outcome were used. The cindex of the nomogram model was the same as that of the main model $(0.81)$, demonstrating that we were able to preserve the predictability of the main model sufficiently after selecting the most important variables. Our results from the 2 hypothetical cases demonstrate that even in the presence of a higher NDI score, as in the patient in case 2 , as long as the work-related factors are more favorable, the patient has a higher probability of returning to work postoperatively.

These nomograms might help surgeons to perform a quick clinical assessment at the time of presentation, thus giving the opportunity to identify at-risk patients and counsel them on their postoperative expectations about return to work and engagement with rehabilitative care.

\section{Study Limitations and Strengths}

We do acknowledge some limitations. First, 1609 patients (24.5\% of the entire eligible cohort) did not fill out 
Points

Age at Surgery

Full time vs Part time

Education Level

Employment

Occupation Intensity

Workers' Compensation

Baseline NDI Score

Symptom Duration

Predominant Symptom

Levels Fused

Total Points

Linear Predictor

Probability of Return to Work
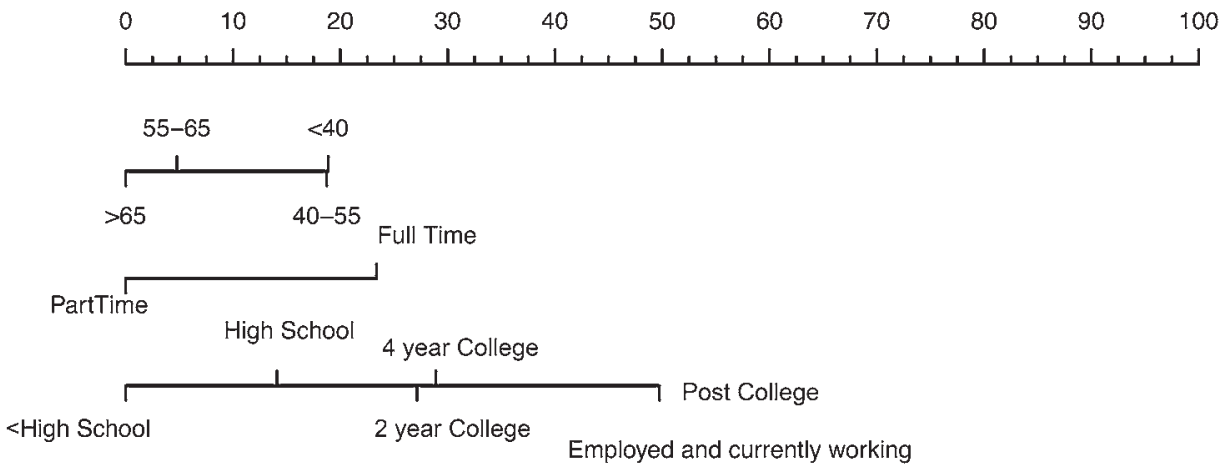

Employed but not working
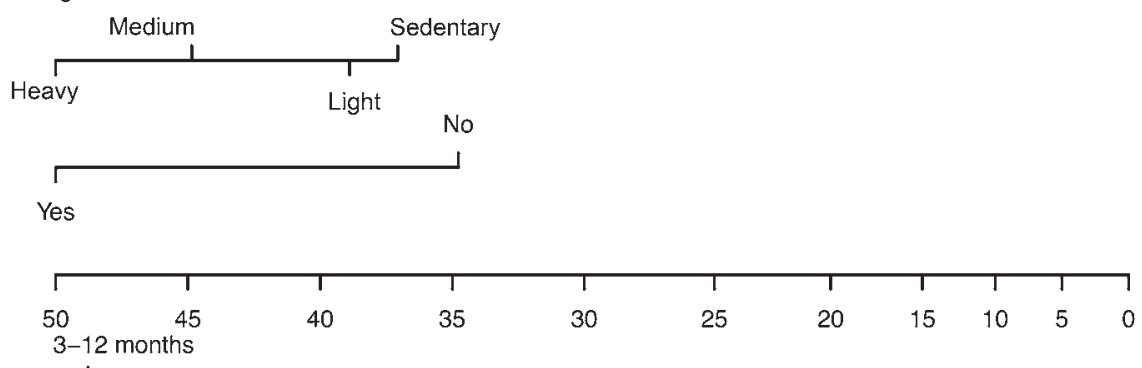

3-12 months

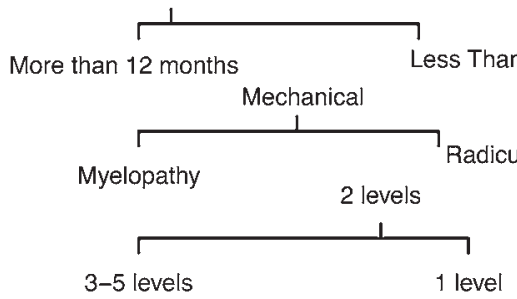

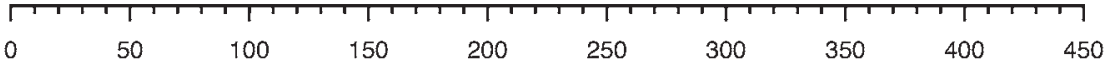

\begin{tabular}{|c|c|c|c|c|c|c|c|c|}
\hline$\Gamma$ & $T$ & $T$ & $T$ & $T$ & 1 & $T$ & $T$ & $T$ \\
\hline-3 & -2 & -1 & 0 & 1 & 2 & 3 & 4 & 5 \\
\hline
\end{tabular}

\begin{tabular}{cccc|c|c|c|ccc|c}
\hline & & & & & & & & & \\
0.05 & 0.1 & 0.2 & 0.3 & 0.4 & 0.50 .6 & 0.7 & 0.8 & 0.9 & 0.95 & 0.99
\end{tabular}

FIG. 3. Nomogram for predicting return to work at 3 months after cervical spine surgery.

a 3-month return-to-work questionnaire, and hence there might have been some selection bias. There is always a chance of selection bias in cases of loss to follow-up that could influence the outcome. Thus, we performed a comparative analysis of the patients included in the final analysis and those who were lost to follow-up. We observed that there was no significant difference in baseline characteristics as well as PROs between the 2 groups (Supplemental Table 3). Second, although model discrimination was excellent (i.e., 0.80), there might be some other variables in addition to those included in our model that may account for the variability in return to work. These might include more granular work-related factors that have been shown to impact return to work. ${ }^{1,8}$ Also, although bootstrap validation adequately assesses the performance of a model, it does not perform as well as external validation, which unfortunately was not pos- sible given the scope of this study. Moreover, we were unable to report on a more granular level the nature of return to work; patients have been shown to return to work in a more limited way, which may still represent a suboptimal outcome.

Nevertheless, our study demonstrates the advantage of using baseline variables that are readily available to determine a comprehensive probability of return to work among patients undergoing a cervical spine surgery. Our predictive model could also help surgeons identify atrisk patients who could then be counseled regarding their postoperative expectations. Ultimately, such efforts could drastically impact the structure of healthcare by evaluating the priorities of the patient and establishing realistic expectations, and hence could drive down cost by avoiding unnecessary surgery in cases in which the expectations might be unrealistic. 
TABLE 5. Nomogram analysis of 2 illustrative cases

\begin{tabular}{|c|c|c|c|c|}
\hline \multirow[b]{2}{*}{ Variable } & \multicolumn{2}{|l|}{ Case 1} & \multicolumn{2}{|c|}{ Case 2} \\
\hline & Value & Points & Value & Points \\
\hline Age at op & $57 \mathrm{yrs}$ & 5 & $41 \mathrm{yrs}$ & 19 \\
\hline $\begin{array}{l}\text { Patient education } \\
\text { level }\end{array}$ & High school & 14 & Postgraduate & 50 \\
\hline Employment status & $\begin{array}{l}\text { Employed but } \\
\text { not working }\end{array}$ & 0 & $\begin{array}{l}\text { Employed \& } \\
\text { working }\end{array}$ & 57 \\
\hline $\begin{array}{l}\text { Employment type } \\
\text { preop }\end{array}$ & Part time & 0 & Full time & 23 \\
\hline Symptom duration & $>12$ mos & 0 & & \\
\hline $\begin{array}{l}\text { Workers' compen- } \\
\text { sation }\end{array}$ & Yes & 0 & No & 38 \\
\hline Occupation intensity & Medium & 13 & Sedentary & 32 \\
\hline $\begin{array}{l}\text { Predominant } \\
\text { symptom }\end{array}$ & Radiculopathy & 27 & Myelopathy & 0 \\
\hline Baseline NDI score & 25 & 61 & 30 & 49 \\
\hline $\begin{array}{c}\text { Fusion levels } \\
\text { planned }\end{array}$ & 1 & 31 & 2 & 23 \\
\hline Total points & & 151 & & 291 \\
\hline $\begin{array}{l}\text { Probability of return- } \\
\text { ing to work }\end{array}$ & & $<20 \%$ & & $90 \%$ \\
\hline
\end{tabular}

\section{Conclusions}

In the present study, we proposed a predictive model for return to work among patients undergoing a cervical spine surgery. We found that work-related factors represent the most important predictors of return to work at 3 months. Using the results of our multivariable regression, we also constructed a nomogram that can be used as a quick assessment of the probability of a patient returning to work by using data readily available to the surgeon. Ultimately, such clinical tools can enhance shared decision-making approaches during preoperative counseling and provide an opportunity to improve patient outcomes and drive down cost in the long term.

\section{References}

1. Anderson PA, Schwaegler PE, Cizek D, Leverson G: Work status as a predictor of surgical outcome of discogenic low back pain. Spine (Phila Pa 1976) 31:2510-2515, 2006

2. Asher AL, Devin CJ, Archer KR, Chotai S, Parker SL, Bydon M, et al: An analysis from the Quality Outcomes Database, Part 2. Predictive model for return to work after elective surgery for lumbar degenerative disease. J Neurosurg Spine 27:370-381, 2017

3. Asher AL, Speroff T, Dittus RS, Parker SL, Davies JM, Selden N, et al: The National Neurosurgery Quality and Outcomes Database ( $\left.\mathrm{N}^{2} \mathrm{QOD}\right)$ : a collaborative North American outcomes registry to advance value-based spine care. Spine (Phila Pa 1976) 39 (22 Suppl 1):S106-S116, 2014

4. Atlas SJ, Tosteson TD, Blood EA, Skinner JS, Pransky GS, Weinstein JN: The impact of workers' compensation on outcomes of surgical and nonoperative therapy for patients with a lumbar disc herniation: SPORT. Spine (Phila Pa 1976) 35:89-97, 2010

5. Berecki-Gisolf J, Clay FJ, Collie A, McClure RJ: Predictors of sustained return to work after work-related injury or disease: insights from workers' compensation claims records. J Occup Rehabil 22:283-291, 2012

6. Bertalanffy H, Eggert HR: Clinical long-term results of anterior discectomy without fusion for treatment of cervical radiculopathy and myelopathy. A follow-up of 164 cases. Acta Neurochir (Wien) 90:127-135, 1988

7. Blumenthal S, McAfee PC, Guyer RD, Hochschuler SH, Geisler FH, Holt RT, et al: A prospective, randomized, multicenter Food and Drug Administration investigational device exemptions study of lumbar total disc replacement with the CHARITE artificial disc versus lumbar fusion: part I: evaluation of clinical outcomes. Spine (Phila Pa 1976) 30:15651575, E387-E391, 2005

8. Cole DC, Ibrahim S, Shannon HS, Scott FE, Eyles J: Work and life stressors and psychological distress in the Canadian working population: a structural equation modelling approach to analysis of the 1994 National Population Health Survey. Chronic Dis Can 23:91-99, 2002

9. Corenman DS, Gillard DM, Dornan GJ, Strauch EL: Recombinant human bone morphogenetic protein-2-augmented transforaminal lumbar interbody fusion for the treatment of chronic low back pain secondary to the homogeneous diagnosis of discogenic pain syndrome: two-year outcomes. Spine (Phila Pa 1976) 38:E1269-E1277, 2013

10. Eriksen EF, Buhl M, Fode K, Klaerke A, Krøyer L, Lindeberg H, et al: Treatment of cervical disc disease using Cloward's technique. The prognostic value of clinical preoperative data in 1,106 patients. Acta Neurochir (Wien) 70:181-197, 1984

11. Franklin GM, Haug J, Heyer NJ, McKeefrey SP, Picciano JF: Outcome of lumbar fusion in Washington State workers' compensation. Spine (Phila Pa 1976) 19:1897-1904, 1994

12. Fritzell P, Hägg O, Jonsson D, Nordwall A, Swedish Lumbar Spine Study Group: Cost-effectiveness of lumbar fusion and nonsurgical treatment for chronic low back pain in the Swedish Lumbar Spine Study: a multicenter, randomized, controlled trial from the Swedish Lumbar Spine Study Group. Spine (Phila Pa 1976) 29:421-434, Z3, 2004

13. Gum JL, Glassman SD, Carreon LY: Is type of compensation a predictor of outcome after lumbar fusion? Spine (Phila Pa 1976) 38:443-448, 2013

14. Hamburger C, Festenberg FV, Uhl E: Ventral discectomy with PMMA interbody fusion for cervical disc disease: longterm results in 249 patients. Spine (Phila Pa 1976) 26:249255, 2001

15. Harrell FE Jr: Regression Modeling Strategies: With Applications to Linear Models, Logistic and Ordinal Regression, and Survival Analysis. New York: Springer, 2001

16. Harrell FE Jr: Regression Modeling Strategies: With Applications to Linear Models, Logistic and Ordinal Regression, and Survival Analysis, ed 2. Cham, Switzerland: Springer, 2015

17. Kato S, Fehlings M: Degenerative cervical myelopathy. Curr Rev Musculoskelet Med 9:263-271, 2016

18. Laaksonen M, Talala K, Martelin T, Rahkonen O, Roos E, Helakorpi S, et al: Health behaviours as explanations for educational level differences in cardiovascular and all-cause mortality: a follow-up of 60000 men and women over 23 years. Eur J Public Health 18:38-43, 2008

19. Lubelski D, Alentado V, Nowacki AS, Shriver M, Abdullah KG, Steinmetz MP, et al: Preoperative nomograms predict patient-specific cervical spine surgery clinical and quality of life outcomes. Neurosurgery 83:104-113, 2018

20. Maxwell TD, Gatchel RJ, Mayer TG: Cognitive predictors of depression in chronic low back pain: toward an inclusive model. J Behav Med 21:131-143, 1998

21. McGirt MJ, Bydon M, Archer KR, Devin CJ, Chotai S, Parker SL, et al: An analysis from the Quality Outcomes Da- 
tabase, Part 1. Disability, quality of life, and pain outcomes following lumbar spine surgery: predicting likely individual patient outcomes for shared decision-making. J Neurosurg Spine 27:357-369, 2017

22. McGirt MJ, Speroff T, Dittus RS, Harrell FE Jr, Asher AL: The National Neurosurgery Quality and Outcomes Database $\left(\mathrm{N}^{2} \mathrm{QOD}\right)$ : general overview and pilot-year project description. Neurosurg Focus 34(1):E6, 2013

23. Mroz TE, Norvell DC, Ecker E, Gruenberg M, Dailey A, Brodke DS: Fusion versus nonoperative management for chronic low back pain: do sociodemographic factors affect outcome? Spine (Phila Pa 1976) 36 (21 Suppl):S75-S86, 2011

24. Nikolaidis I, Fouyas IP, Sandercock PA, Statham PF: Surgery for cervical radiculopathy or myelopathy. Cochrane Database Syst Rev (1):CD001466, 2010

25. Peolsson A, Peolsson M: Predictive factors for long-term outcome of anterior cervical decompression and fusion: a multivariate data analysis. Eur Spine J 17:406-414, 2008

26. Robertson PA, Jackson SA: Prospective assessment of outcomes improvement following fusion for low back pain. J Spinal Disord Tech 17:183-188, 2004

27. Stewart WF, Ricci JA, Chee E, Morganstein D, Lipton R: Lost productive time and cost due to common pain conditions in the US workforce. JAMA 290:2443-2454, 2003

28. Wang MC, Kreuter W, Wolfla CE, Maiman DJ, Deyo RA: Trends and variations in cervical spine surgery in the United States: Medicare beneficiaries, 1992 to 2005. Spine (Phila Pa 1976) 34:955-963, 2009

29. Zigler JE, Rogers RW, Ohnmeiss DD: Comparison of 1-level versus 2-level anterior cervical discectomy and fusion: clinical and radiographic follow-up at 60 months. Spine (Phila Pa 1976) 41:463-469, 2016

\section{Disclosures}

Dr. Archer is a consultant for Pacira, Palladian Health, and NeuroPoint Alliance, Inc.; and is on the scientific advisory board for APTA. Dr. Bisson is a consultant for nView. Dr. Devin is a consultant for Wright Medical and Stryker Spine; and is an expert witness for Medtronic. Dr. Foley is a consultant for Medtronic; has direct stock ownership in Discgenics, Medtronic, NuVasive,
SpineWave, and TrueVision; is a patent holder with Medtronic and NuVasive; and is on the board of directors for Discgenics and TrueVision. Dr. Knightly is on the board of directors for NeuroPoint Alliance. Dr. Mummaneni is a consultant for DePuy Spine, Globus, and Stryker; has direct stock ownership in Spinicity/ISD; has received clinical or research support for the study described (including equipment or material) from NREF; has received support of a non-study-related clinical or research effort that he oversees from ISSG; and has received honoraria from AO Spine and Spineart, and royalties from DePuy Spine, Thieme Publishing, and Springer Publishing. Dr. Shaffrey is a consultant for Medtronic, NuVasive, Zimmer-Biomet, and EOS; has direct stock ownership in NuVasive; and is a patent holder with Medtronic, NuVasive, and Zimmer-Biomet.

\section{Author Contributions}

Conception and design: Bydon, Devin, Alvi, Sivaganesan. Acquisition of data: Alvi. Analysis and interpretation of data: Alvi, Kerezoudis. Drafting the article: Bydon, Devin, Alvi. Critically revising the article: all authors. Reviewed submitted version of manuscript: Bydon, Devin, Kerezoudis, Khan, Sivaganesan, McGirt, Archer, Foley, Mummaneni, Bisson, Knightly, Shaffrey, Asher. Approved the final version of the manuscript on behalf of all authors: Bydon. Statistical analysis: Alvi. Administrative/technical/material support: Bydon, Devin, Kerezoudis, Khan, Sivaganesan, McGirt, Archer, Foley, Mummaneni, Bisson, Knightly, Shaffrey, Asher. Study supervision: Bydon, Devin, Khan, Sivaganesan, McGirt, Archer, Foley, Mummaneni, Bisson, Knightly, Shaffrey, Asher.

\section{Supplemental Information \\ Online-Only Content}

Supplemental material is available with the online version of the article.

Supplemental File. https://thejns.org/doi/suppl/10.3171/2018. 8.FOCUS18326.

\section{Correspondence}

Mohamad Bydon: Mayo Clinic, Rochester, MN. bydon. mohamad@mayo.edu. 